On the present theory it would not be necessary for the abnormal montmorillonites recently described by Bose and Sengupta ${ }^{5}$ to have iron contents intermediate between that of nontronite and normal montmorillonite to explain the lower differential thermal peak in the region $500^{\circ}-700^{\circ} \mathrm{C}$. Another naturally abnormal montmorillonite known to me has no iron at all, and the iron content of the sample used by Hill ${ }^{6}$ could not have been changed during his experiments. Chemical data indicate also that current theories of the effect of substitution of silicon by aluminium in tetrahedral layers do not explain the thermal effects of anomalous illites and montmorillonites. A disorder-order process seems worthy of serious consideration and study.

In the scheme suggested, a cycle of transformations is postulated, and this cycle should be reversible; but as yet no ways of performing the disorder-order transformation artificially have been found. However, this concept should enable one to plan experiments designed to transform illite and montmorillonite (normal forms) into each other more suceessfully than has been done in the past.

A more detailed account of these ideas is given in a chapter on clay mineral mixtures and mixed-layer minerals in the forthcoming monograph of the Mineralogical Society of Great Britain on "The Differential Thermal Investigation of Clays". W. F. CoLE

Division of Building Research

(Commonwealth Scientific and

Industrial Research Organization), Graham Road,

Highett, S.21, Victoria. Sept. 27.

2 Bystrom, A. M., Nature, 173, 783 (1954). Cole, W. F., and Carthew, A. R., J. Roy. Soc. Tas., 87, 1 (1953). Heystek, H., Min. Mag 30,400 (1954). Weaver, C. E., Bull. Geol. Soc. Amer., 64, 92 (1953).

"Brown, G., and MacEwan, D. M. C., in "X-Ray Identification and Structures of Clay Minerals", edit. G. W. Brindley, $266(1950)$.

${ }^{3}$ MacEwan, D. M. C., Nature, 172, 364 (1953).

4Mackenzie, R. C., Walker, G. F., and Hart, R., Min. Mag., 28, 704 (1949).

${ }^{6}$ Bose, A. K., and Sengupta, P., Nature, 174, 40 (1954).

- Hill, R. D., Trans. Brit. Ceram. Soc., 52, 589 (1953).

" Kerr, P. F., Kulp, J. L., and Hamilton, P. K., "Differential Thermal Analygis of Reference Clay Mineral Specimens", Report 3, American Petroleum Institute Project 49 (Columbia University, New York, 1949).

\section{Anhydrous Hydrogen Fluoride as a Collagen Solvent}

$I_{T}$ has been reported ${ }^{1}$ that hide collagen and other proteins dissolve in anhydrous hydrogen fluoride. The fact that some proteins, like insulin, were recovered with up to 80 per cent of their initial biological activity, after solution in this solvent, suggested that collagen might dissolve without denaturation. The ability to reconstitute characteristic collagen fibrils from solution was used as the criterion of the absence of denaturation.

Dry, purified, unlimed, steer-hide collagen was introduced into the middle flask of a train of three polyethylene flasks. These flasks were connected to each other, to the hydrogen fluoride tank, and to a nitrogen tank by polyethylene and copper tubing to form a gas-tight apparatus. After introduction of the sample, the apparatus was flushed with dried nitrogen for $48 \mathrm{hr}$. Hydrogen fluoride was distilled from the tank into the nearest flask and then carefully redistilled into the flask containing the sample. After eleven days at $0^{\circ} \mathrm{C}$, some of the collagen had dissolved. Using anhydrous conditions, some of the supernatant liquid was withdrawn into a fourth polyethylene flask. The hydrogen fluoride was evaporated from the two flasks anhydrously and the residues examined.

The residue from the supernatant liquid was a transparent film which gave a gelatin-like high-angle X-ray diffraction diagram. This dry film was soluble in water. A distilled water solution of this film produced precipitates when ammonium sulphate and phosphotungstic acid solutions were added. These precipitates were examined in the electron microscope but nothing fibrous was observed.

The distilled water solution was further examined by dialysis against 1 per cent and 10 per cent solutions of sodium chloride, tap water and distilled water. Bovine glycoprotein was added to another portion, and this mixture was dialysed against distilled water ${ }^{2}$. Precipitates were not obtained in these reconstitution tests, and nothing fibrous was seen on electron microscopic examination.

We conclude that anhydrous hydrogen fluoride does dissolve steer hide collagen, but that the solution occurs with denaturation.

$$
\text { Russeit E: DreIKorN }
$$$$
\text { VINCENT O'GORMAN }
$$

Research Division,

United Shoe Machinery Corporation, Beverly, Massachusetts. Oct. 20.

${ }^{1}$ Katz, J. J., Nature, 173, 265 (1954). 2 Highberger, J. H., Gross, J., and Schmitt, F. O., Proc. U.S. Nat.
Acad. Sci., 37, 286 (1954).

\section{Reactions of Hyponitrites and Nitrites}

EXPERIMENTs carried out by Oza and Oza ${ }^{1}$ with silver and anhydrous strontium hyponitrites and dinitrogen tetroxide at $0^{\circ}, 30^{\circ}$ and $140^{\circ} \mathrm{C}$. show the production, in the gas, of both nitrous oxide and nitrogen, which are among the thermal decomposition products of these hyponitrites. It appears, therefore, that these hyponitrites undergo fission into their normal decomposition products under the impact of the molecules of nitrogen tetroxide or dioxide. The oxide and the nitrite so formed then react with the nitrogen tetroxide or dioxide to yield their relevant products of the reaction, while the gaseous products of the primary fission remain unaltered and their presence is shown by analysis of the gas.

It is known that sodium hyponitrite decomposes as follows :

$$
3 \mathrm{Na}_{2} \mathrm{~N}_{2} \mathrm{O}_{2}=2 \mathrm{Na}_{2} \mathrm{O}+2 \mathrm{NaNO}_{2}+2 \mathrm{~N}_{2}
$$

The hydrated salt produces some nitrous oxide also ${ }^{1}$. Thus the mere presence of water has the effect of converting some of the nitrogen into nitrous oxide. Calcium hyponitrite tetrahydrate, which normally decomposes into nitrite, nitrate, oxide, nitrous oxide, nitric oxide and nitrogen at $330^{\circ}$, is shown to decompose, yielding the same products, when kept for some time in the vicinity of $100^{\circ}$. It appears, therefore, that the decomposition of hyponitrites can be induced by causes other than heat, for example, by molecular agitation of some kind. The hyponitrites of strontium, silver and mercury have slso been systematically investigated by Oza and Thaker and found to yield similar products when decomposed by heat. 